\title{
Anatomical Study on the Safety of Anterior Cervical Craniovertebral Fusion with Clival Screw Placement in Children Aged I-6 Years
}

\author{
Shao-Jie Zhang ${ }^{1,2, *}$ \\ Kun $\mathrm{Li}^{2,3, *}$ \\ Zhi-Jun $\mathrm{Li}^{2,3}$ \\ Xing Wang ${ }^{2,3}$ \\ Jia-Hui Dong ${ }^{4}$ \\ Jian Wang ${ }^{2}$ \\ Jie Chen ${ }^{2}$ \\ Xing-Yue $\mathrm{Qu}{ }^{2}$ \\ Zi-Yu Li ${ }^{2}$ \\ Yu-Hang Liu ${ }^{2}$ \\ 'School of Traditional Chinese Medicine, \\ Beijing University of Chinese Medicine, \\ Beijing, People's Republic of China; \\ ${ }^{2}$ Department of Human Anatomy, Inner \\ Mongolia Medical University, Hohhot, \\ People's Republic of China; ${ }^{3}$ Digital \\ Medical Center, Inner Mongolia Medical \\ University, Hohhot, People's Republic of \\ China; ${ }^{4}$ The First Clinical Medical \\ College, Inner Mongolia Medical \\ University, Hohhot, People's Republic of \\ China
}

*These authors contributed equally to this work

\begin{abstract}
Objective: This study aimed to investigate the safety of clival screw placement in children aged 1-6 years.

Methods: The cranial computed tomography data of 92 children aged 1-6 years were divided into three groups, according to age, for three-dimensional reconstruction. Three clival screw placement points were defined: (1) median point $\mathrm{A}$ at the middle and upper third of the tripartite distance from the spheno-occipital synchondrosis to the base of the skull; $(2,3)$ critical points $\mathrm{B}$ and $\mathrm{C}$ on the horizontal line with point $\mathrm{A}$, where the screw placement passage was parallel to the sagittal plane. Parameters such as the passage length and angle were measured for horizontal, vertical facial, and extreme screw placement.

Results: The length parameters of the clival screw placement increased with age, and the screw passage length was the shortest for the vertical facial type in each age group. There were significant differences in all three groups between the length of screw placement in the vertical bone surface, the length of screw placement in the horizontal direction, and the length of screw placement on the limit at points $\mathrm{A}, \mathrm{B}$, and $\mathrm{C}(P<0.05)$; the length of screw placement on the vertical bone surface was the shortest. There was no significant difference between the horizontal screw length at point $\mathrm{A}$ and the extreme screw length $(P>0.05)$. The difference between the horizontal screw length and the extreme screw length in the groups aged 1-2 years and 5-6 years was statistically significant $(P<0.05)$, and the horizontal screw length was longer.

Conclusion: The cranial slope of children aged 1-6 years has the morphological basis for the placement of $3.5 \mathrm{~mm}$ screws, and each placement point has a safe angle range for screw placement.
\end{abstract}

Keywords: children, craniocervical junction region, clivus, internal screw fixation, spiral computed tomography scan

\section{Introduction}

The craniocervical junction region (CCJR) is a key junction and mechanical bridge connecting the brain and cervical vertebra. With special morphology and structure and a complex function, it allows the multidimensional movement of the head and neck and provides mechanical support. The CCJR in children is more prone to inflammation, tumor, trauma, deformity, and pressure on the medulla oblongata and spinal cord, which can threaten life. ${ }^{1-5}$ Therefore, surgical removal and internal fixation are often required to maintain stability. ${ }^{6-9}$ The most common methods of fixation are a subarticular atlantoaxial locking plate, a transoral atlantoaxial reduction plate, a Harms titanium plate, and a fabricated cage. ${ }^{10-12}$
Correspondence: Zhi-Jun Li

Department of Human Anatomy, Inner Mongolia Medical University, Hohhot,

People's Republic of China

Tel +86 47I-6636945

Email zj106_master@126.com 
Recently, a 12-year-old boy with congenital skull-base depression was reported to have undergone odontoidectomy and internal fixation with plates and screws between the slopes and vertebral body. ${ }^{13}$ Reconstruction using a titanium cage directly fixed between the slope and the vertebral body after resection of the ventral lesions of the upper cervical spine has also been reported. ${ }^{14,15}$ Therefore, clival screws can be used for the resection of lesions and reconstruction of craniocervical connections in patients with abnormalities, and this internal fixation method is considered to be more stable than others. ${ }^{16}$ Ji developed a plate-screw system for transcranial clival internal fixation by measuring clival image data in adults, showing through biomechanical experiments that the system had good stability. ${ }^{17,18}$ However, few studies have been conducted on anterior clival screw placement in children. ${ }^{13,19}$

Children aged 1-6 years have much smaller clival structures, and the middle of the clivus is split by the spheno-occipital synchondrosis, which is the basilar growth center; clinical screw placement in this growth center cannot be performed (see Figure 1I). ${ }^{20}$ Therefore, simple scaled-down adult or adolescent data on clival screw placement cannot be used for developing children.

With the development of digital medicine, image data can be reconstructed and post-processed using three-dimensional (3D) reconstruction software, which can visually and stereoscopically display and arbitrarily cut slices to observe the parameters of clival screw placement. ${ }^{21-23}$ Chen et al showed that there is no significant difference between reconstructed measurement data and backbone data. Therefore, it can be assumed that $3 \mathrm{D}$ reconstruction measurements are consistent with backbone measurement data and can provide parameters and the basis for the clinical application of clival screw placement. $^{24}$
In the present study, the basic parameters of clival screw placement in 92 healthy children aged 1-6 years were obtained using the $3 \mathrm{D}$ reconstruction and cutting measurements of their craniocervical spiral computed tomography (CT) scan thin-slice image data. The anatomical feasibility of $3.5 \mathrm{~mm}$ screw placement in children in this age range was evaluated, thereby providing a theoretical basis for the placement and design of clival internal fixation using plates and screws for children aged 1-6 years.

\section{Materials and Methods Demographics}

The spiral CT scan image data of the CCRJ of 92 healthy children aged 1-6 years were collected at the First and Second Affiliated Hospitals of the Inner Mongolia Medical University and the International Mongolian Hospital between September 2016 and May 2019 (GE LightSpeed QX/I 64-slice spiral CT scan, with a slice thickness and spacing of $0.625 \mathrm{~mm}$, field of view $30 \times 30 \mathrm{~cm}$, and matrix of $512 \times 512 \mathrm{dpi}$ ). Image data of clival anomalies caused by occipitocervical fractures, deformities, neoplasms, and other diseases were excluded. The data were divided into three groups based on the age of the children: group A (1years, $n=30)$; group $B(3-$ years, $n=31)$; group C (5-6 years, $n=31$ ). Each parameter was measured three times by the same physician, and the result was recorded as an average of the three measurements.

This study was conducted in accordance with the Declaration of Helsinki and approved by the Ethics Committee of the Inner Mongolia Medical University. Written informed consent was obtained from the parents of all subjects.
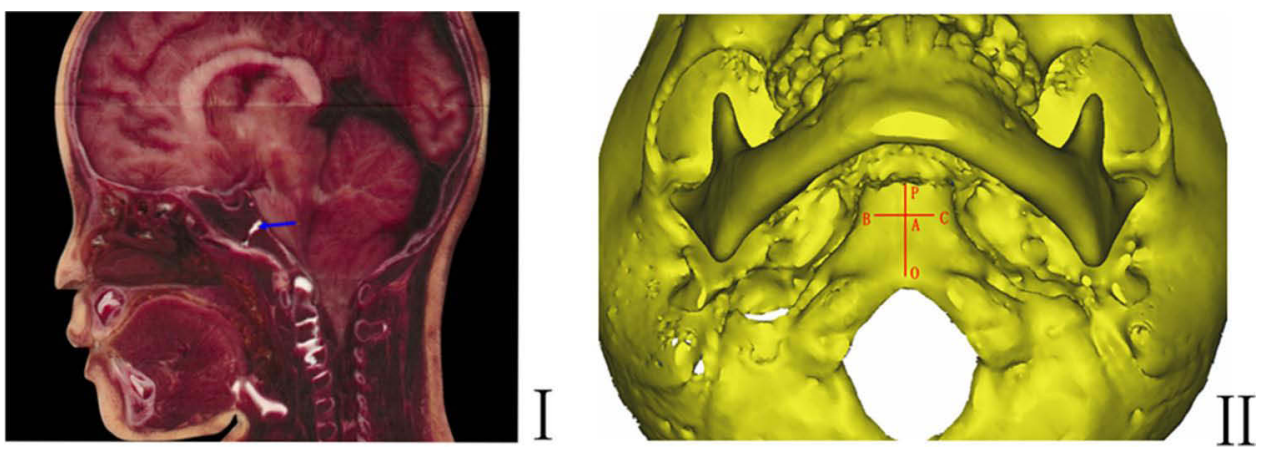

Figure I Schematic diagram for measuring the length parameters of spheno-occipital articulation and screw placement in children's cranial slopes. (I) Central sagittal craniocervical view of a healthy six-year-old child (arrow pointing to spheno-occipital cartilage junction). (II) Lop is the length of the extracranial spheno-occipital cartilage junction to the base of the slope; $L_{A B}$ is the length between screw placement points $A$ and $B$; $L_{A C}$ is the length between screw placement points $A$ and $C$. 


\section{Measurement Methods}

The collected image data were imported into the Mimics Innovation Suite 16.0 (Materialise, Belgium) in DICOM format. Thresholding tools were employed in segmentation to select the appropriate $\mathrm{HU}$ thresholds to generate a bone mask and edit masks. Region growing tools were used to separately produce a skull mask for 3D reconstruction. Once this had been created, the mask was edited in 3D and separated, and other cutting tools in the software were used to cut the sagittal plane on the $3 \mathrm{D}$ reconstruction model. Finally, distance- and angle-measurement tools were used to measure the relevant index parameters on the reconstruction model.

The length of the extracranial spheno-occipital cartilage junction to the base of the slope $\left(\mathrm{L}_{\mathrm{OP}}\right)$ was measured on the model (see Figure 1II). Previous studies have reported that the clival spheno-occipital synchondrosis in children is the basilar growth center, so screws cannot be placed there (see Figure 1I). Furthermore, the thinness of the bone in the lower clivus means it is unsuitable for screw placement. Therefore, allowing for the anatomical characteristics of the clivus in children, the clival screw placement points designed in the present study were set as those on the horizontal line of point A, which was on the median line of the basilar clivus, and the middle and upper third of the tripartite distance from the spheno-occipital synchondrosis to the base of the skull. However, some researchers have proposed that the minimum safe distance between the screws and the slope edge is $2 \mathrm{~mm}$, that is, the entry point of the clival screw (diameter $3.5 \mathrm{~mm}$ ) should be at least $3.75 \mathrm{~mm}$ from the bone cortex on both sides of the slope. ${ }^{19}$ Therefore, critical clival screw placement points $\mathrm{B}$ and $\mathrm{C}$ were set $3.75 \mathrm{~mm}$ from the cortex margin of the left and right side of the clivus on the horizontal line with point A (see Figure 1II). Since clival screw fixation can either be achieved using a median single screw or a left and right double screw fixation, the clival screw placement points in this study were set as the median point $\mathrm{A}$ and critical points $\mathrm{B}$ and $\mathrm{C}$, and the screw passage was parallel to the sagittal plane.

On the $3 \mathrm{D}$ reconstruction model, the sagittal planes of three points $\mathrm{A}, \mathrm{B}$, and $\mathrm{C}$ were cut. The screw was inserted in the three sagittal maps in three different ways: (1) horizontal screw placement, in which the screw was parallel to the horizontal plane and intersected with the intracranial slope at point $\mathrm{A} ;(2)$ vertical screw placement, in which the screw placement channel was perpendicular to the tangent line of the bone surface of the extracranial ramp and intersected with the intracranial ramp at point B; (3) extreme screw placement, in which the screw placement channel was from the screw placement point to the junction of the spheno-occipital cartilage and intracranial slope, which intersected with the intracranial slope at point $\mathrm{B}$. The length and angle of the screw were measured (see Figure 2). Finally, the lengths of $\mathrm{L}_{\mathrm{AB}}$ and $\mathrm{L}_{\mathrm{AC}}$ were measured (see Figure 1II).

To avoid adjacent tissue damage and ensure that screws with enough length to achieve mechanical stability were placed, the outer edge of the clival bone cortex was used as the boundary for length measurement. To measure the angle, the vertical screw was inserted first, after which the tangent line of the extracranial ramp was used as a reference to measure the angle between the tangent line and the screw.

\section{Statistical Methods}

SPSS 20.0 statistical software was used for data processing, and measurement data were expressed as mean \pm
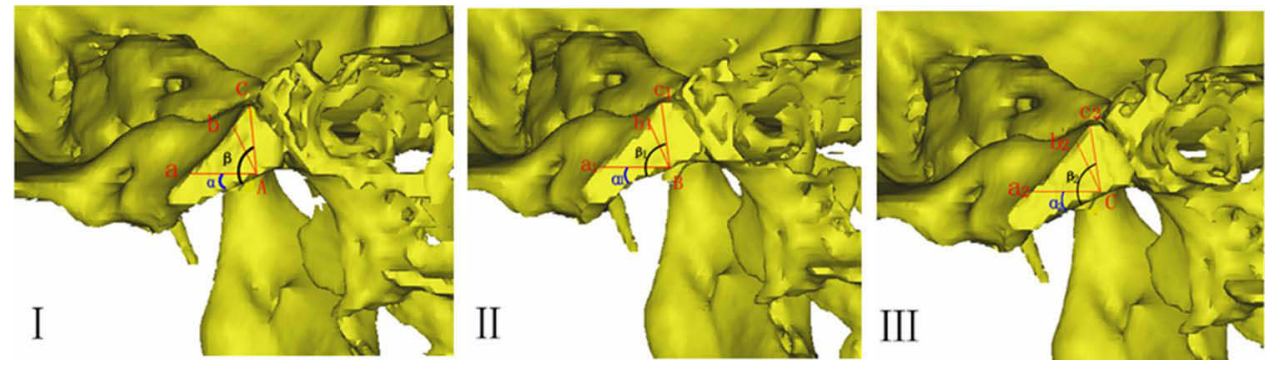

Figure 2 Schematic diagram of the angle and length measurement of different screw placement methods on children's cranial slopes. (I) Point A of clival screw placement in the middle sagittal position of the reconstructed model. The lengths $L_{A A}, L_{A B}$, and $L_{A C}$ in horizontal screw placement, vertical bone screw placement, and extreme screw placement, as well as the horizontal entry angle $\alpha$ and the ultimate entry angle $\beta$, were used at point A. (II) The reconstructed model was 3.75 mm away from the sagittal screw placement (point $B$ ) at the left edge of the slope. At point $B$, the lengths of screw placement $L_{B A I}, L_{B B I}$, and $L_{B C I}$ in horizontal screw placement, vertical bone screw placement, and extreme screw placement, and the horizontal entry angle $\alpha \mathrm{I}$ and the ultimate entry angle $\beta \mathrm{I}$, respectively, were used. (III) The reconstructed model was $3.75 \mathrm{~mm}$ away from the right edge of the slope at sagittal screw placement point $C$. The length of screw placement at point $C$ was $\mathrm{L}_{\mathrm{CA} 2}$, $\mathrm{L}_{\mathrm{CB} 2}$, $\mathrm{L}_{\mathrm{CC} 2}$ in horizontal screw placement, vertical bone screw placement, and extreme screw placement, respectively. Approach angle $\alpha 2=$ horizontal screw placement; approach angle $\beta 2=$ extreme screw placement. 
standard deviation $(\overline{\mathrm{x}} \pm \mathrm{s})$. One-way analysis of variance was used when the data within a group met the normal requirements for homogeneity of variance. A least significant difference test was used for pairwise comparison. $P<$ 0.05 was considered statistically significant.

\section{Results}

\section{Measurement Results of Different Age} Groups at Clival Screw Placement Points As can be seen in Table 1, the length from the sphenooccipital cartilage junction to the base of the slope $\left(\mathrm{L}_{\mathrm{OP}}\right)$, the length of screw placement point $\mathrm{A}$ to point $\mathrm{B}\left(\mathrm{L}_{\mathrm{AB}}\right)$, and the length of screw placement point $A$ to point $C\left(\mathrm{~L}_{\mathrm{AC}}\right)$ all showed an increasing trend with age. There were statistically significant differences in $\mathrm{L}_{\mathrm{OP}}$ and $\mathrm{L}_{\mathrm{AB}}$ between the three age groups $(P<0.05)$. The $\mathrm{L}_{\mathrm{AC}}$ of group $\mathrm{A}$ was significantly different from that of group $\mathrm{B}$ and group $\mathrm{C}(P<0.05)$.

\section{Measurement Results of Clival Screw Placement Lengths in Different Age Groups}

As can be seen in Table 2, the lengths of the horizontal, vertical facial, and extreme screw placement at $\mathrm{A}, \mathrm{B}$, and $\mathrm{C}$ increased with age. Apart from the horizontal length of screw placement points $\mathrm{A}$ and $\mathrm{C}$, all the length parameters showed statistically significant differences between the three age groups $(P<0.05)$. Compared with groups $\mathrm{B}$ and $\mathrm{C}$, the difference of the horizontal length of the screw placement point A in group A was statistically significant $(P<0.05)$. Compared with group $\mathrm{A}$ and $\mathrm{B}$, the difference of the horizontal length of the screw placement point $\mathrm{C}$ in group $\mathrm{C}$ was statistically significant $(P<0.05)$.

Table I Measurement Results of Relevant Parameters of Slope Screw Placement in Each Age Group (mm) $[\bar{x} \pm \mathbf{s}, \quad(95 \%$ Confidence Interval)]

\begin{tabular}{|c|c|c|c|}
\hline Group A & Group B & Group C \\
\hline $\mathrm{L}_{\mathrm{OP}}$ & $\begin{array}{c}15.5 \pm 0.8 \\
(15.2,15.8)\end{array}$ & $\begin{array}{c}19.1 \pm 1.5 \\
(18.6,19.6) *\end{array}$ & $\begin{array}{c}21.1 \pm 1.8 \\
(20.5,21.7) * \#\end{array}$ \\
\hline $\mathrm{L}_{\mathrm{AB}}$ & $\begin{array}{c}5.67 \pm 0.63 \\
(5.44,5.92)\end{array}$ & $\begin{array}{c}6.36 \pm 0.92 \\
5.97,6.65) *\end{array}$ & $\begin{array}{c}6.90 \pm 0.87 \\
(6.61,7.26) * *\end{array}$ \\
\hline $\mathrm{L}_{\mathrm{AC}}$ & $\begin{array}{c}5.66 \pm 0.61 \\
(5.42,5.90)\end{array}$ & $\begin{array}{c}6.84 \pm 0.95 \\
(6.45,7.15)^{*}\end{array}$ & $\begin{array}{c}7.14 \pm 0.92 \\
(6.81,7.50)^{*}\end{array}$ \\
\hline
\end{tabular}

Notes: $L_{O P}$ is the length between the sphenoccipital cartilage junction of the slope and the base of the slope, $L_{A B}$ is the $A B$ length of the screw placement point, and $L_{A C}$ is the $A C$ length of the screw placement point. *Compared with group $A, P<$ 0.05 ; \#Compared with group B, $P<0.05$.

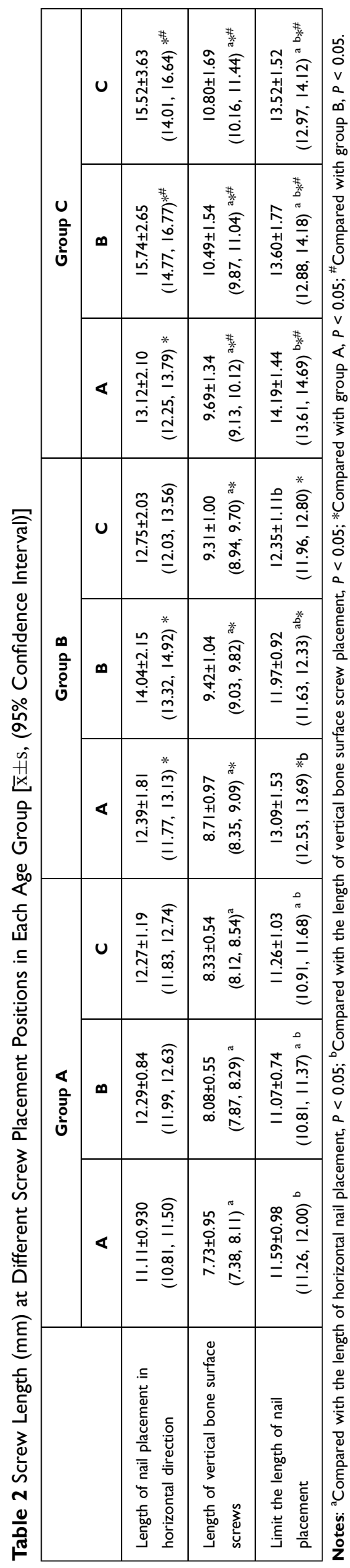


There was a statistically significant difference between the vertical bone surface screw placement length, the horizontal screw placement length, and the extreme screw placement length at screw placement points $\mathrm{A}, \mathrm{B}$, and $\mathrm{C}$ in all three groups $(P<0.05)$. However, there was no significant difference between the horizontal screw length and the extreme screw length at screw placement point $\mathrm{A}$ in any of the groups $(P>0.05)$. The difference between the horizontal screw length and the extreme screw length at placement points $\mathrm{B}$ and $\mathrm{C}$ in groups $\mathrm{A}$ and $\mathrm{C}$ was statistically significant $(P<0.05)$, but this difference was not found in screw placement point $\mathrm{C}$ in group $\mathrm{B}$.

\section{Measurement Results of the Clival Screw Placement Angles in Different Age Groups}

No statistically significant differences were found in the angles of the horizontal screw placement types between the three age groups $(P>0.05)$. However, a statistically significant difference between group $\mathrm{A}$ and group $\mathrm{C}$ was observed in the extreme angle $\beta$ of the screw placement point A $(P<0.05$; see Table 3$)$.

\section{Discussion}

Children's slopes have their own structural development characteristics, so it is challenging and risky to implement screw placement in them. Only by fully understanding the morphological characteristics of children's cranial slopes and analyzing the rules of clival screw positioning, orientation, and depth setting can clival screws be placed more accurately.

Due to the complex and important anatomical structures in and around children's cranial slopes, the area for safe placement of screws is relatively small. The children's cranial slope consists of the sphenoid and occipital bones, which are connected by the spheno-occipital cartilage. ${ }^{25-27}$ This cartilaginous union is the longitudinal growth center of the skull base, and bone fusion occurs after adolescence. ${ }^{28-31}$ Therefore, screw placement should avoid the sphenooccipital junction. In addition, the sagittal plane of the clivus is similar to an inverted triangle, with a wide top and a narrow bottom. Therefore, the thinner bone in the lower part of the clivus may have poor screw-holding force, making it unsuitable for screw placement. ${ }^{17,18}$ A previous study performed imaging measurements on the clival internal fixation of children aged 2-16 years and defined the correct screw placement point as the midpoint of the full length of the

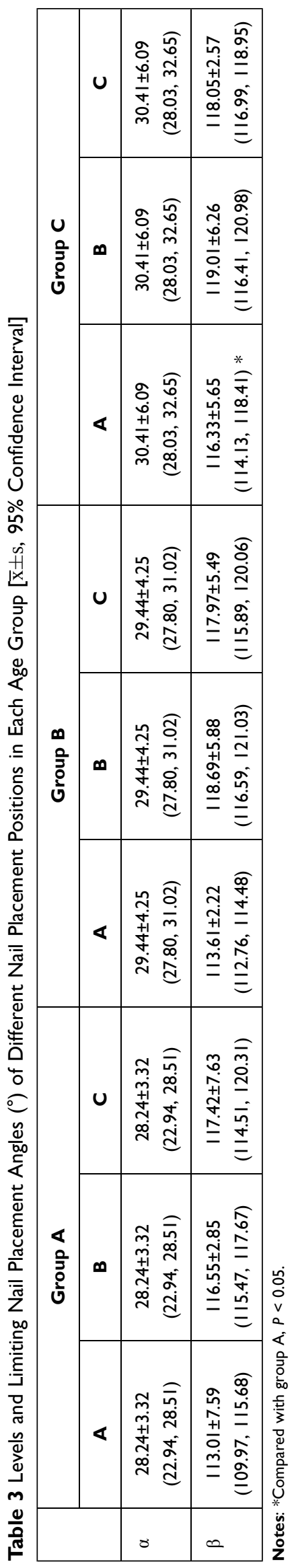


extracranial clivus. ${ }^{19}$ However, this may be too close to the spheno-occipital synchondrosis in some children to allow for the placement of screws. ${ }^{20}$ In the present study, allowing for the anatomical characteristics of the clivus in children, the clival screw placement points were defined as the median point $\mathrm{A}$ at the middle and upper third of the tripartite distance from the spheno-occipital synchondrosis to the base of skull and critical points $\mathrm{B}$ and $\mathrm{C}$ on the horizontal line with point A, where the screw placement passage is parallel to the sagittal plane. The clival screw can be fixed with a single central screw (point A) or two left- and right-side screws (points B and C).

Some researchers have proposed that the minimum safe length between the edge of the screw and the edge of the slope should be $2 \mathrm{~mm},{ }^{19}$ that is, the insertion point of a $3.5 \mathrm{~mm}$ screw (radius of $1.75 \mathrm{~mm}$ ) and the bone cortex of the edge of the slope should be at least $3.75 \mathrm{~mm}$. In the present study, the length of $\mathrm{L}_{\mathrm{OP}}$ was $15.5 \mathrm{~mm}$ in group A, $19.1 \mathrm{~mm}$ in group $\mathrm{B}$, and $21.1 \mathrm{~mm}$ in group C. After trisection, it was placed at point A (when fixed with a single central screw). The length from the spheno-occipital cartilage union of the three groups was $5.2 \mathrm{~mm}, 6.4 \mathrm{~mm}$, and $7.0 \mathrm{~mm}$, respectively, all of which are larger than $3.75 \mathrm{~mm}$, therefore meeting the requirements of placement. This shows that a single central screw can be inserted into a child's cranial slope. When two screws are fixed, the safe distance between the edges of the screws is $2 \mathrm{~mm}$, that is, the safe distance between the edges of each screw and the midline is greater than $1 \mathrm{~mm}$. Therefore, the safe distance between the placement point and the midline is the sum of the radius of each screw $(1.75 \mathrm{~mm})$ and the safe distance: $2.75 \mathrm{~mm}$. In the present study, the minimum screw placement length was measured in group $\mathrm{A}$, showing a $\mathrm{L}_{\mathrm{AB}}$ length of $5.67 \pm 0.63 \mathrm{~mm}$ and a $\mathrm{L}_{\mathrm{AC}}$ length of $5.66 \pm 0.61 \mathrm{~mm}$; the safe distance of double screw placement was far greater than that of double screw placement. This shows that double screw placement can be used in children.

Another important factor in screw placement is direction. The tangent line of the surface of the cranial slope is used as a reference point: if the angle is too small, the surgical approach is limited because the sphenoid sinus, soft palate, nasal cavity, and other important anatomical structures are adjacent to the front of the slope. ${ }^{19}$ If the placement angle is too large, the screw is easily inserted into the spheno-occipital cartilage junction. In the present study, the safe range of the clival screw setting angle in horizontal screw placement was the range between the angle of the screw path and the slope bone surface, while the safe range in extreme screw placement was between the angle of the screw path and the slope bone surface. In group $\mathrm{A}$, the safe screw angles at points $\mathrm{A}, \mathrm{B}$, and $\mathrm{C}$ were $28.24-113.01^{\circ}, 28.24-116.55^{\circ}$, and 28.24117.42, respectively. In group $\mathrm{B}$, the safe screw angles at points $\mathrm{A}, \mathrm{B}$, and $\mathrm{C}$ were $29.44-113.61^{\circ}, 29.44-118.69^{\circ}$, and $29.44-117.97^{\circ}$, respectively. In group $C$, the safe screw angles at points $\mathrm{A}, \mathrm{B}$, and $\mathrm{C}$ were $30.41-116.33^{\circ}$, $30.41-119.01^{\circ}$, and $30.41-118.05^{\circ}$, respectively. Previous research has found that adult vertical osseous screw placement is the best angle because of the better operating space. $^{18}$

The length of clival screw placement is proportional to the screw-holding force and pulling force. The intracranial slope is closely adjacent to the medulla oblongata, cranial nerve, and other structures, so the screws inserted cannot penetrate the intracranial cortex. The results of the present study show that the passage length parameters for clival screw placement in children increase with age. Statistically significant differences were also found in all groups between the length of vertical bone surface screw placement, the length of horizontal screw placement, and the length of extreme screw placement; it was also found that the length of horizontal screw placement and extreme screw placement were longer. Clinically, vertical facial screw placement is often used due to its more suitable operating space compared with the other screw placement types. However, the length of the inserted screw in vertical facial screw placement is shorter than in other screw placement methods. Therefore, a surgical approach should be designed in advance based on the patient's condition, with the surgical area exposed. Horizontal or extreme screw placement should be employed where possible in order to increase the length of the screw placement passage.

In the present study, the length of the horizontal screw at point $\mathrm{A}$ was compared with the length of the extreme screw in single-screw fixation in the center; no statistically significant differences were found in any of the groups, indicating that both methods of screw placement are suitable. With regard to double-screw fixation, the horizontal screw positioning lengths of screw points $\mathrm{B}$ and $\mathrm{C}$ were compared with the extreme screw positioning length (other than point $\mathrm{C}$ in group $\mathrm{B}$ ); a statistically significant difference was found, and the horizontal screw was longer, indicating that horizontal screw placement should be employed. 


\section{Conclusion}

It is feasible to insert $3.5 \mathrm{~mm}$ screws at different angles on cranial slopes in children aged 1-6 years. The appropriate placement points are the median point $\mathrm{A}$ of the upper middle third of the distance trisection between the sphenooccipital cartilage and the skull base and critical points $\mathrm{B}$ and $\mathrm{C}$ of the horizontal line with point $\mathrm{A}$. The screw channel can be placed parallel to the sagittal plane. The safe angle range of the clival screw placement for horizontal placement is the range between the angle of the screw placement path and the slope bone surface in the horizontal direction of each screw placement point, while the safe angle range for extreme screw placement is the range between the angle of the screw placement path and the slope bone surface. When fixed with a single screw in the center, horizontal screw placement or extreme screw placement can be used. When two screws are fixed, horizontal screw placement should be used in order to maximize the length of the screw channel. However, clival morphological development varies greatly between individuals and within an individual. In order to avoid severe intraoperative complications, conventional spiral CT scans and $3 \mathrm{D}$ reconstruction are required to determine the optimal location of screws before surgery.

\section{Funding}

National Natural Science Foundation of China (81660358, 81860382, 81860383, 81560348); Undergraduate Innovation and Entrepreneurship Project of Inner Mongolia Medical University (20201032001); The Inner Mongolia autonomous region of natural science fund project (2019MS08017, 2020LH08021, 2020MS03061).

\section{Disclosure}

The authors report no conflicts of interest in this work.

\section{References}

1. Hale AT, Say I, Shah S, et al. Traumatic occipitocervical distraction injuries in children: a systematic review. Pediatr Neurosurg. 2019;54 (2):75-84. doi:10.1159/000496832

2. Helenius IJ, Bauer JM, Verhofste B, et al. Os odontoideum in children: treatment outcomes and neurological risk factors. J Bone Joint Surg Am. 2019;101(19):1750-1760. doi:10.2106/JBJS.19.00314

3. Tian YL, Xu NF, Yan M, et al. Atlantoaxial dislocation with congenital "sandwich fusion" in the craniovertebral junction: a retrospective case series of 70 patients. BMC Musculoskelet Disord. 2020;21(1):821. doi:10.1186/s12891-020-03852-8

4. Miura I, Aihara Y, Mitsuyama T, et al. Basilar invagination in a child with atlanto-occipital subluxation and suspected prenatal DandyWalker malformation. Childs Nerv Syst. 2019;35(8):1429-1434. doi:10.1007/s00381-019-04164-6
5. Adib O, Berthier E, Loisel D, Aubé C. Pediatric cervical spine in emergency: radiographic features of normal anatomy, variants and pitfalls. Skeletal Radiol. 2016;45(12):1607-1617. doi:10.1007/ s00256-016-2481-9

6. Vedantam A, Hansen D, Briceño V, Brayton A, Jea A. Patientreported outcomes of occipitocervical and atlantoaxial fusions in children. J Neurosurg Pediatr. 2017;19(1):85-90. doi:10.3171/ 2016.8.PEDS16286

7. Abel TJ, Yan H, Canty M, et al. Traumatic atlanto-occipital dislocation in children: is external immobilization an option? Childs Nerv Syst. 2021;37(1):177-183. doi:10.1007/s00381-020-04680-w

8. Garrido BJ, Sasso RC. Occipitocervical fusion. Orthop Clin North Am. 2012;43(1):1-9. doi:10.1016/j.ocl.2011.08.009

9. Menezes AH. Craniocervical fusions in children. $J$ Neurosurg Pediatr. 2012;9(6):573-585. doi:10.3171/2012.2.PEDS11371

10. Yin Q-S, Ai F-Z, Zhang K, et al. Transoral atlantoaxial reduction plate internal fixation for the treatment of irreducible atlantoaxial dislocation: a 2- to 4-year follow-up. Orthop Surg. 2010;2 (2):149-155. doi:10.1111/j.1757-7861.2010.00077.x

11. Kandziora F, Pflugmacher R, Ludwig K, et al. Biomechanical comparison of four anterior atlantoaxial plate systems. J Neurosurg. 2002;96(3 Suppl):313-320.

12. Guppy KH, Chakrabarti I, Isaacs RS, et al. En bloc resection of a multilevel high-cervical chordoma involving C-2: new operative modalities: technical note. J Neurosurg Spine. 2013;19(2):232-242. doi:10.3171/2013.5.SPINE121039

13. Goel A, Karapurkar AP. Transoral plate and screw fixation of the craniovertebral region-a preliminary report. $\mathrm{Br} J$ Neurosurg. 1994;8:743-745. doi:10.3109/02688699409101191

14. Suchomel P, Buchvald P, Barsa P, et al. Single-stage total C-2 intralesional spondylectomy for chordoma with three-column reconstruction. Technical Note. J Neurosurg Spine. 2007;6:611-618. doi:10.3171/spi.2007.6.6.17

15. Rawlins JM, Batchelor AG, Liddington MI, et al. Tumor excision and reconstruction of the upper cervical spine: a multidisciplinary approach. Plast Reconstr Surg. 2004;114:1534-1538. doi:10.1097/ 01.PRS.0000138239.12968.31

16. Sar C, Eralp L. Transoral resection and reconstruction for primary osteogenic sarcoma of the second cervical vertebra. Spine. 2001;26 (17):1936-1941. doi:10.1097/00007632-200109010-00025

17. Ji W, Tong J, Huang Z, et al. A clivus plate fixation for reconstruction of ventral defect of the craniovertebral junction: a novel fixation device for craniovertebral instability. Eur Spine J. 2015;24:1658-1665. doi:10.1007/s00586-015-4025-8

18. Ji W, Wang XY, Xu HZ, et al. The anatomic study of clival screw fixation for the craniovertebral region. Eur Spine J. 2012;21 (8):1483-1491. doi:10.1007/s00586-012-2151-0

19. Ji W, Kong -G-G, Zheng M-H, et al. Computed tomographic morphometric analysis of pediatric clival screw placement at the craniovertebral junction. Spine. 2015;40(5):259-265. doi:10.1097/ BRS.0000000000000749

20. Krmpotic-Nemanic J, Vinter I, Kelovizc Z, et al. Postnatal changes of the clivus. Ann Anat. 2005;187(3):277-280. doi:10.1016/j. aanat.2004.11.005

21. $\mathrm{Hu} \mathrm{ZS}$, Vergari C, Gajny L, et al. Comparison of 3D and 2D characterization of spinal geometry from biplanar X-rays: a large cohort study. Quant Imaging Med Surg. 2021;11:3306-3313. doi:10.21037/qims-20-861

22. Wang QA, Guo C, Sun MJ, et al. Three-dimensional spiral CT observation of the facet joints of the lower cervical spine and its clinical significance. Eur Spine J. 2021;30(6):1536-1541. doi:10.1007/s00586-021-06743-1

23. Li Y, Lin J, Wang Y, et al. Comparative study of 3D printed navigation template-assisted atlantoaxial pedicle screws versus free-hand screws for type II odontoid fractures. Eur Spine J. 2021;30 (2):498-506. doi:10.1007/s00586-020-06644-9 
24. Chen QF, Xiao ZM, Zhang ZM, et al. Sectional anatomy of atlas pedicle screw technique and application of 3d CT. Chin J Clin Anat. 2009;27(2):166-169.

25. Iscan MY, Steyn M. The Human Skeleton in Forensic Medicine (M). Royal Society of Medicine Press; 2013:48.

26. Hofmann E, Prescher A. The clivus: anatomy, normal variants and imaging pathology. Clin Neuroradiol. 2012;22(2):123-139. doi:10.1007/s00062-011-0083-4

27. Kanchan T, Krishan K. Evaluation of spheno-occipital synchondrosis: a review of literature and considerations from forensic anthropologic point of view. J Forensic Dent Sci. 2013;5(2):72-76. doi:10.4103/ 0975-1475.119764

28. Akhlaghi M, Taghaddosinejad F, Sheikhaxadi A, et al. Age-at-death estimation based on the macroscopic examination of spheno-occipital sutures. J Forensic Leg Med. 2010;17(6):304-348. doi:10.1016/j. jflm.2010.04.009
29. Hoyte DA. The cranial base in normal and abnormal skull growth. Neurosurg Clin N Am. 1991;2(3):515-537. doi:10.1016/S10423680(18)30715-0

30. Rosenberg P, Arlis HR, Haworth RD. The role of the cranial base in facial growth: experimental craniofacial synostosis in the rabbit. Plast Reconstr. 1997;99(5):1396-1407. doi:10.1097/00006534199705000-00030

31. Rodgers WB, Coran DL, Kharrazi FD, et al. Increasing lordosis of the occipitocervical junction after arthrodesis in young children: the occipitocervical crankshaft phenomenon. J Pediatr Orthop. 1997;17 (6):762-765. doi:10.1097/01241398-199711000-00011

\section{Publish your work in this journal}

The International Journal of General Medicine is an international, peer-reviewed open-access journal that focuses on general and internal medicine, pathogenesis, epidemiology, diagnosis, monitoring and treatment protocols. The journal is characterized by the rapid reporting of reviews, original research and clinical studies across all disease areas. The manuscript management system is completely online and includes a very quick and fair peer-review system, which is all easy to use. Visit http://www.dovepress.com testimonials.php to read real quotes from published authors. 